\title{
The role of social networks in supporting the travel needs of people after serious traumatic injury: a nested qualitative study
}

\section{The abstract}

This study explores the importance of social networks and transport for people who had experienced a traumatic injury three years earlier. Many participants found travelling difficult because of pain, discomfort, fatigue and mobility impairments caused by their injuries which led them to be highly dependent on being a passenger in cars driven by others, or on public transport and taxis, to meet their travels needs. After injury, participants' needs to travel were often high because they had to attend regular medical and physiotherapy appointments. They also needed to be able to travel to reengage with social activities. For those who used public transport or taxis, new challenges were faced in terms of the preplanning, lack of accessibility and availability of these modes. Participants that lived in rural areas with infrequent public transport keenly felt their dependence on others for transport as did those who were wheelchair dependent where car based travel was the only option. Participants described their dependence on others for travel as feeling they were a burden. For some participants their social network could not help with travel. This meant that they either did not travel or had to absorb the costs of taxis. Practical support from the Transport Accident Commission compensation scheme in terms of taxi vouchers were useful and appreciated. However, the service provided by taxis was perceived as costly and, at times, described as unreliable and unsafe. There were many hidden costs related to supporting the travel needs of injured people. Participants who could not travel and reengage with social activities felt emotionally low, isolated and vulnerable. Service providers need to consider injured people's ability to access support for travel, the availability of accessible transport and help with travel costs in order to support their physical and psychological recovery.

Key words: social networks; social support; travel; mobility; trauma

\section{Introduction}

The term social network describes both the informal relationships and connectivity between an individual and family and friends and the formal networks of other people who are important to a person such as colleagues at work etc. (Barnes, 1954). Social networks and the social support they provide are known to be important for health (e.g. Smith et al, 2008; Berkman and Glass, 2000). Transport is known to play a major role in sustaining social networks by satisfying peoples need to be physically co-present with members of their network ( e.g. Urry, 2003; Cass et al, 2005). There is an increasing understanding of the nexus between transport, social interactions and health. Boniface et al 2015 reviewed the evidence on the relationships between transport, social interactions and the consequences for health and wellbeing. They identified the importance of transport accessibility and trip making for wellbeing as it provides access to social networks and social participation. When access to transport is diminished this can lead to social isolation which negatively affects health and wellbeing. Moreover, research shows that access to transport is a mediating factor that facilitates mobility and social participation - acknowledged as key determinants of health and quality of life (Levasseur et al. 2015; SEU, 2003).

When a person's mobility is, or becomes restricted this can lead to social exclusion and poor health outcomes. For example, cessation of driving among older people has been linked to depression (Marottoli et al, 1997). Arguably, people who are ill or injured often experience a high need for transport not only to access health care but to tap into their social networks as these can facilitate recovery by providing emotional, psychological and practical support (Barclay et al. 2016 Prang et al, 2015). However, research has shown that transport issues can provide a major barrier to accessing health care (Cox et al, 2012; Syed et al, 2013). Similarly, people who have experienced a serious injury may experience challenges travelling because of impaired mobility (Lyons et al, 2011). Studies (Barclay et al, 2016; Carpenter et al, 2007) have shown that people who had a major trauma such as spinal cord injury found it difficult to access appropriate private or public transport, which was 
essential for them to reengage with social activities. People who travelled with a spinal cord injury had to expend considerable effort and energy and 'battled' to get to places only to find that the built and natural environments were inaccessible to them.

Research has shown the importance of social support for health and role of transport in accessing and maintaining those social support networks; however, few studies have explored, in detail, the role that social networks play in supporting the travel needs and desires of traumatically injured people whose mobility is impaired and the consequences of this for maintaining those social networks. This paper explores the importance of social networks in supporting the transport needs and desires of a sample traumatically injured people in Australia and the implications of this for managing their wellbeing at this time of change and vulnerability.

The study reported here was set in Victoria, Australia and was part of the REcovery after Serious Trauma-Outcomes, Resource use and patient Experiences (RESTORE) project which explored the recovery trajectories and impacts of injury of traumatically injured people. Between 2012-13 46,680 Australians were hospitalised because of an injury (Pointer, 2015). Each year approximately 3000 Victorians are seriously injured. This project used both qualitative and quantitative methods to gain a comprehensive overview of long-term patient outcomes and experiences at 3, 4 and 5 years postinjury.

\section{Method}

The methods of this project have been previously described in detail (Gabbe, et al 2015). Major trauma was defined as including any of the following: (i) death related to injury; (ii) an injury severity score (ISS) $>12$; (iii) admission to an intensive care unit (ICU) for $>24$ hours and requiring mechanical ventilation for at least part of their ICU stay, and (iv) urgent surgery. For people injured in road or rail transport crashes, irrespective of fault, the Transport Accident Commission (TAC) provides compensation for treatment, rehabilitation, disability, income replacement and long-term support services.

The state of Victoria operates a regionalised trauma system, where pre-hospital and hospital services are integrated to ensure injured patients are delivered to the most appropriate facilities in the shortest possible time. The Victorian State Trauma Registry (VSTR) is a population-based registry capturing data about all major trauma patients in Victoria. The VSTR contains clinical and demographic information on all major trauma patients and is used to monitor the performance and effectiveness of the Victorian trauma system. All eligible cases are included on the registry unless they choose not to take part, which is less than $0.4 \%$ of participants (Cameron et al, 2005). In the 2014-15 financial year, the VSTR recorded 3,073 hospitalised major trauma patients managed by the Victorian State Trauma system. (Department of Health, 2014).

The study was approved by the Monash University Human Research Ethics Committee and participating trauma-receiving hospitals. Two adult hospitals and one pediatric hospital are designated major trauma services that manage and provide definitive care to seriously injured people. To be eligible for the study, patients needed to be 16 years or older, registered with the VSTR with a date of injury from 1 July 2011 to 30 June 2012, survived to hospital discharge, and not have withdrawn their consent to be part of the registry. Due to resource constraints, we could only interview Englishspeaking participants. After completing the structured 3-year follow-up interview, an invitation was extended to participate in an in-depth interview. 
For the RESTORE project 2,757 adult patients were followed-up 36-months post-injury. Of these patients, there were 333 in hospital deaths and 2424 survivors to discharge. A further 222 patients had died post-discharge by 36 months. Of the 2202 adult survivors at 36 months, 1850 responders were asked if they were willing to participate in an in-depth interview. Two hundred and ninety-eight adults expressed an interest, and of these 114 were purposively selected. Those who agreed were purposively sampled based on age, gender, compensation status, residential location (metropolitan or regional), and whether they received care at a major trauma service or not. Using a topic guide, three experienced interviewers performed the interviews between July 2014 and July 2015. Open-ended questions explored areas such as the modes of transport used, any changes in transport since the injury, any impacts on home, community, work and social participation, and any relationships affected since the injury. Participants' responses directed any subsequent prompts or questions. Most interviews took between 30 and 60 mins to complete. All interviews were audio recorded and transcribed and verbal consent to participate was recorded at the start of the interview.

Thematic content analysis (Braun and Clarke, 2006) was conducted on the data using NVivo software where we selected all quotes that mentioned transport and within those we coded where this was linked to social networks. This involved a number of stages. Firstly, the researchers immersed themselves in the data by reading the transcripts several times and making initial notes to develop a set of codes which described important messages in the transcripts. Five transcripts were subjected to this process first with four researchers examining these independently to explore consistency and reliability of the coding scheme. Secondly, the coding scheme was refined and used to code subsequent transcripts. Thirdly, for each code relevant verbatim text was extracted with enough text to provide information on the context and tagged using NVivo software to make the data readily retrievable. For this paper, the text coded in relation to transport issues was extracted and reviewed to explore patterns in the data related to social networks and to describe the prevalent themes. Finally, a thematic map was developed to show the themes and how they related to each other.

Selected verbatim quotes from a diverse range of participants were used to illustrate the themes. The characteristics of the participants are given in parentheses after the quote and denote:

- Gender

- Area: Regional or metropolitan Melbourne

- Interview type: Patient or proxy (if proxy, type mother, spouse etc.)

- Trauma category; Major (serious injury without SCI or TBI), traumatic brain injury (TBI), spinal cord injury (SCI)

- Transport related or non-transport related

- Age at injury date

- Summary of injuries sustained

\section{Results}

\subsection{Participant characteristics}

We conducted in-depth interviews with 114 adults (16 years or older), 3 years after the injury event. If the injured person was unable to participate, a proxy was interviewed. Fifteen proxy interviews were 
conducted with a parent, spouse or sister of the injured person, because the injured participants had a severe traumatic brain injury (TBI).

Most of the injuries were unintentional $(\mathrm{n}=105,93 \%)$, involved males $(\mathrm{n}=81,71 \%)$ and most were aged under 60 years $(n=83,73 \%)$. Over half of the participants $(n=61,54 \%)$ were injured because of a transport collision, with half of these being compensable by the TAC. All participants had experienced a major trauma. Around a fifth involved a SCI $(n=23,20 \%)$ and another fifth involved traumatic brain injury $(\mathrm{n}=25,22 \%)$. The majority of participants $(71 \%)$ were coping with a moderate or severe disability 3 years post injury and, of those working prior to the injury, over a third had not returned to work (Table $1)$.

Table 1: Participant characteristics $(n=114)$

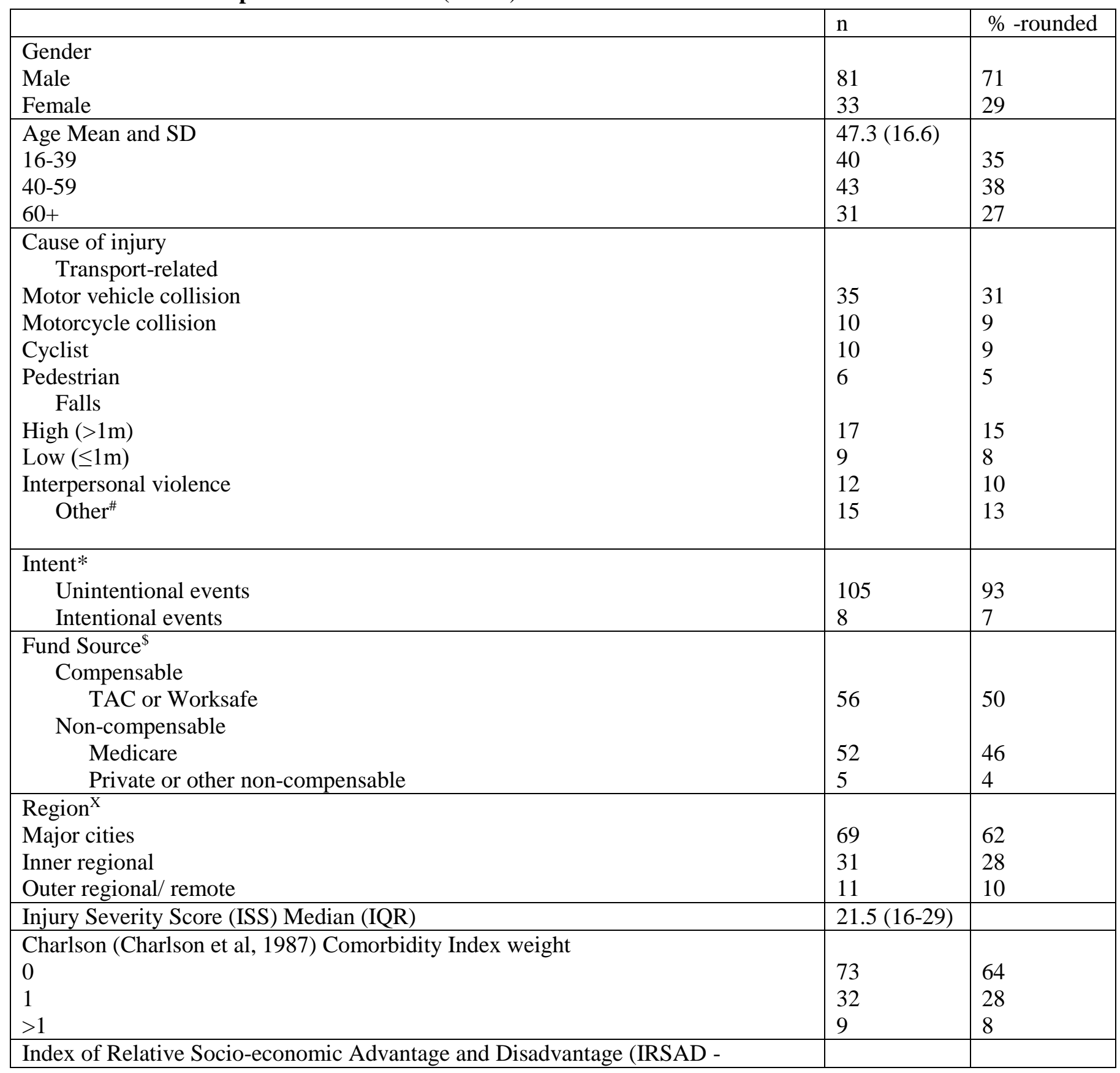




\begin{tabular}{|l|l|l|}
\hline Australian Bureau of Statistics ${ }^{1 \text { \$\$ }}$ & 10 \\
2 (most disadvantaged) & 16 & 14 \\
3 & 26 & 23 \\
4 & 30 & 27 \\
5 (most advantaged) & 28 & 25 \\
& & \\
\hline Pre injury disability & & \\
No & 100 & 89 \\
Yes & 14 & 11 \\
\hline Injury group & & \\
Traumatic brain injury-mild to moderate (TBI) & 25 & 22 \\
Spinal cord injury (SCI) & 23 & 20 \\
Major trauma without TBI or SCI & 66 & 58 \\
\hline Glasgow Outcome Scale-Extended (GOS-E, Wilson et al, 1998)** & $\mathbf{3 6}$ months & \\
Upper good recovery & 24 & 21 \\
Lower good recovery & 9 & 8 \\
Upper moderate disability & 33 & 29 \\
Lower moderate disability & 24 & 21 \\
Upper severe disability & 10 & 9 \\
Lower severe disability & 14 & 12 \\
\hline Work prior to injury & 86 & 75 \\
Return to work at 36 months (of those working prior) & 54 & 63 \\
\hline
\end{tabular}

${ }^{\#}$ Other=horse related; other threat to breathing; fire, flames, smoke; firearm; cutting, piercing object; struck by or collision with object or person; machinery; electricity; and other specified and unspecified external cause.

Missing data: ${ }^{\$} \mathrm{n}-1 ; * \mathrm{n}=1 ;{ }_{\mathrm{n}=3} ;{ }^{\$} \mathrm{n}=3$

**Collapsed from 8 categories

\subsection{Themes}

An overarching theme from the analysis of transcripts was the relationship between social networks and the participant's ability to travel. Three years after their injury this theme emerged as an important issue for around a third of the participants. Described below are the subthemes which illustrate the nature of the importance of the relationship between social networks and people's ability to travel after traumatic injury.

\subsubsection{Dependence on others for transport}

For many participants pain, discomfort and lack of physical mobility meant that their independent mobility was heavily circumscribed. Some participants either had stopped driving or had rarely driven because of their injuries:

There are a lot of things I've stopped. I never bothered with driving again because I had a stiff neck and I felt as though that might be a bit faulty to drive. I've got half-fare taxis and I've got one son in (name of suburb) that takes me to certain medical appointments.

(Female, Metro, Patient, Major, Transport related, 72, Thoracic and spinal cord injuries, lower limb fractures and other injuries).

\footnotetext{
${ }^{1}$ http://www.abs.gov.au/ausstats/abs@.nsf/Lookup/2033.0.55.001main+features100042011-)
} 
For participants with a traumatic brain injury the experience of becoming quickly fatigued (a known sequelae of brain injury (McInnes et al, 2017)) was a problem that meant they could not cope with driving or riding especially for long periods:

I used to spend a hell of a lot of time in a car. One of my best mates lives in (name of suburb) and I live in the northern suburbs of Melbourne, it's about an hour and a half drive, so unless I can get someone to come with me I can't go out there anymore.

(Male, Metro, Patient, Traumatic Brain Injury, Transport related, 33, Head injuries)

This loss of independent mobility occurred at a time when participants needed to travel to attend appointments for medical treatment and/or physiotherapy on a regular basis. Most were highly dependent on friends and relatives to provide transport. Calling on social networks to help with travel to access services was a key feature of many of the participants' narratives:

.. my husband took me at first because there was no way I would have been able to manage getting out the door and getting along the drive and getting into the physiotherapist's without some help, because my injuries really were quite painful and I wasn't very manoeuvrable and didn't have a lot of stamina.

(Female, Regional, Patient, Major, Transport related, 63, Head injury, spinal, pelvic and lower limb fractures).

\subsubsection{Engaging with social activities}

Many participants depended on friends and family to provide transport so that they could reengage in social activities:

I have been very fortunate in that I've got a bunch of friends who live quite close to home and that, they have been excellent with me. There's always one guy happy to come and pick me up if we're heading out for dinner or something like that.

(Male, Metro, Patient, Traumatic Brain Injury, Non transport related, 24, Head and other injuries).

Some felt vulnerable because of their injury and this was exacerbated by the inability of their social networks to meet their needs/desires to travel because, for example, their friends or families were working:

When you're in a brace that restricts you from going to the toilet and driving or walking, it makes you feel very vulnerable as far as what you expect people to do for you...... My daughter worked, my son works, and they are not in a situation where they were sitting there next to me all day at my beck and call. So you go through a lot of emotional stuff when you're lying there on your back and unable to move.

(Male, Metro, Patient, Major, Non-transport related, 61, Spinal and rib fractures, thoracic injury).

Some participants who had been active members of their social networks and were providers of social support to others found that their lack of mobility and inability to travel meant that they could no longer provide that support:

I struggled to get to see my mum. So during that time my mum was very incapacitated. So I couldn't afford to go and just get a taxi across to see my mum in (name of suburb), so sort of six to seven weeks after my accident, I hadn't seen my mum, and I used to do her shopping 
every weekend as well, so I used to do her shopping. So then that went on to another brother to try and do ... who had to travel an hour each way to go and do that.

(Female, Metro, Patient, Major, Transport related, 60, Sternal fracture, carotid artery tear).

For some not being able to travel meant that their social participation was less and this was described as 'difficult " suggesting a sense of loss of social contact with friends and relatives:

All my hobbies involved being physically capable. I really enjoyed working on and racing and fixing, anything to do with cars, but I find it very, very difficult to do any of that now, if at all. Lots of outdoor sports and cycling, different work, leisure activities, so nothing's the same anymore. It's even hard for me to drive around and visit people. You spend so much time on your own, you don't know what to do any more socially.

(Male, Metro, Patient, Major, Transport related, 28, Multiple fractures and other injuries).

\subsubsection{Environmental barriers}

For many wheelchair users their ability to engage with their social network became difficult because they found the environment inaccessible:

When you're in a wheelchair you ... wheelchairs don't like going on grass. Wheelchairs don't like mud. Wheelchairs don't like stones. So to get around it limits you, put it that way.

(Male, Regional, Patient, Spinal Cord Injury, Transport related, 50, Spinal cord ), head, thoracic injuries and multiple fractures).

Inaccessibility was particularly felt by wheelchair users who lived in rural areas who had to negotiate difficult terrains and who became frustrated about not being able to engage with normal social activities or work:

I want to be involved what me kids were doing, going to football. I want to be able to go out to ... yeah; I want to be able to be what they want to be. I want to be able to go to the farm. I want to do what I want to do, when I'm wanting to do it, not be bloody restricted just because I live in the country.

(Male, Regional, Patient, Spinal Cord Injury, Transport related, 62, Cervical fractures and spinal cord injury).

\subsubsection{Emotional burden}

Many participants keenly felt the dependence on others. Friends and relatives observed that the injured person described themselves as a burden on their family and suggested they would prefer not to travel rather than having to depend on them

He's been an independent person for a long time and he couldn't drive his car, he couldn't get out of the house. We used to help him. If he wanted to go somewhere we'd take him, but then he just felt it was such a burden on us that he wouldn't go anywhere, he'd stay at home more than he'd go out, which affected his social life, his friends......... in the beginning, after the accident, it was over a year or so he was completely dependent upon us to drive him around, yes, to do things for him.

(Male, Metro, Proxy, Traumatic Brain Injury, Transport related, 24, Head and thoracic injuries, multiple fractures).

Some participants directly expressed this feeling of being a burden: 
I wasn't able to drive. And even now, driving from (name of suburbs) to visit my mum, who obviously doesn't drive anymore, is a hassle, which is another burden I put on my husband. On his day off, "Can you drive me over to see my mum?"

(Female, Metro, Patient, Major, Transport related, 46, Head, thoracic and dental injuries, spinal fractures).

\subsubsection{The role of taxis}

Where participants could no longer drive themselves, or did not have access to or want to travel by public transport, taxis became important because they could provide personal automobility which helped support their social network. Taxi vouchers enabled participants to have reduced fares on taxis and helped maintain their social networks:

And getting from $A$ to $B$, the half price taxi card has been very, very useful for me. And I'm also very lucky, again, just to say that I've got friends who live quite close to me and so they're able to come and pick me up whenever they're heading out somewhere.

(Male, Metro, Patient, Traumatic Brain Injury, Non-transport related, 24, Head and other injuries.

However, whilst the vouchers were helpful in reducing the costs of taxis, many had to pay the full price of taxis in order to maintain their social networks and this was a financial burden:

There'll be taxi to me mum. Taxi to me brother. So I spend \$50, \$100 there - Friday to Monday. Tuesday, Wednesday, Thursday, Friday, till the afternoon, is all TAC. Friday afternoon till Sunday night is me own taxi fares, I have to pay for me own taxi to get wherever I'm travelling. That's been a costly event.

(Female, Metro, Patient, Major, Transport related, 46, Head, thoracic and dental injuries, spinal fractures).

However, relying on taxis was often problematic because of their lack of reliability and a 'bit of a joke' if you lived in a rural area:

... the taxis didn't always turn up. And a couple of times they didn't turn up and I had appointments. It wasn't as if I'd booked it half-an-hour before, it was booked hours before. And they're just scary ... to drive in a car with a taxi driver straight after an accident, that's just beyond scary.

(Female, Metro, Patient, Major, Transport related, 46, Thoracic and orthopaedic injuries.

For one participant with a spinal injury only some taxis were accessible and these were hard to book:

There was two taxis in (name of rural area), but I could only fit into one. You couldn't have them through school hours, you couldn't have them in the afternoons because they ... well, you could, if you were going to a medical appointment in Melbourne they had to take ya. But normally you couldn't have them till 10 o'clock in the morning; you had to be finished at 3 o'clock in the afternoon.

(Male, Regional Patient, Spinal Cord Injury,Transport related, 62, Cervical fractures and spinal cord laceration C6).

\section{Discussion}


Our participants reflected on the last three years since their injury and about the changes they had made to the way they travelled post injury. Our study showed that transport issues were a frequently mentioned as a component of social participation decision-making 3-years after injury.

Our study has shown that the ability to travel after injury has an important influence on the extent that people can access the services they need and reconnect with their social support networks. Many of the severely injured people depended on their social support networks in order to travel for goods and services and to reengage with social activities. People who are unable to travel and reengage with their social networks may feel isolated and vulnerable, negatively affecting wellbeing and recovery.

The relationship between the social support network of an injured person and their ability to travel is multidirectional and associated with both positive and negative potential outcomes (see Figure 1).

Figure 1. Thematic map showing relationships between social networks and transport and the potential impacts on injured people's wellbeing.

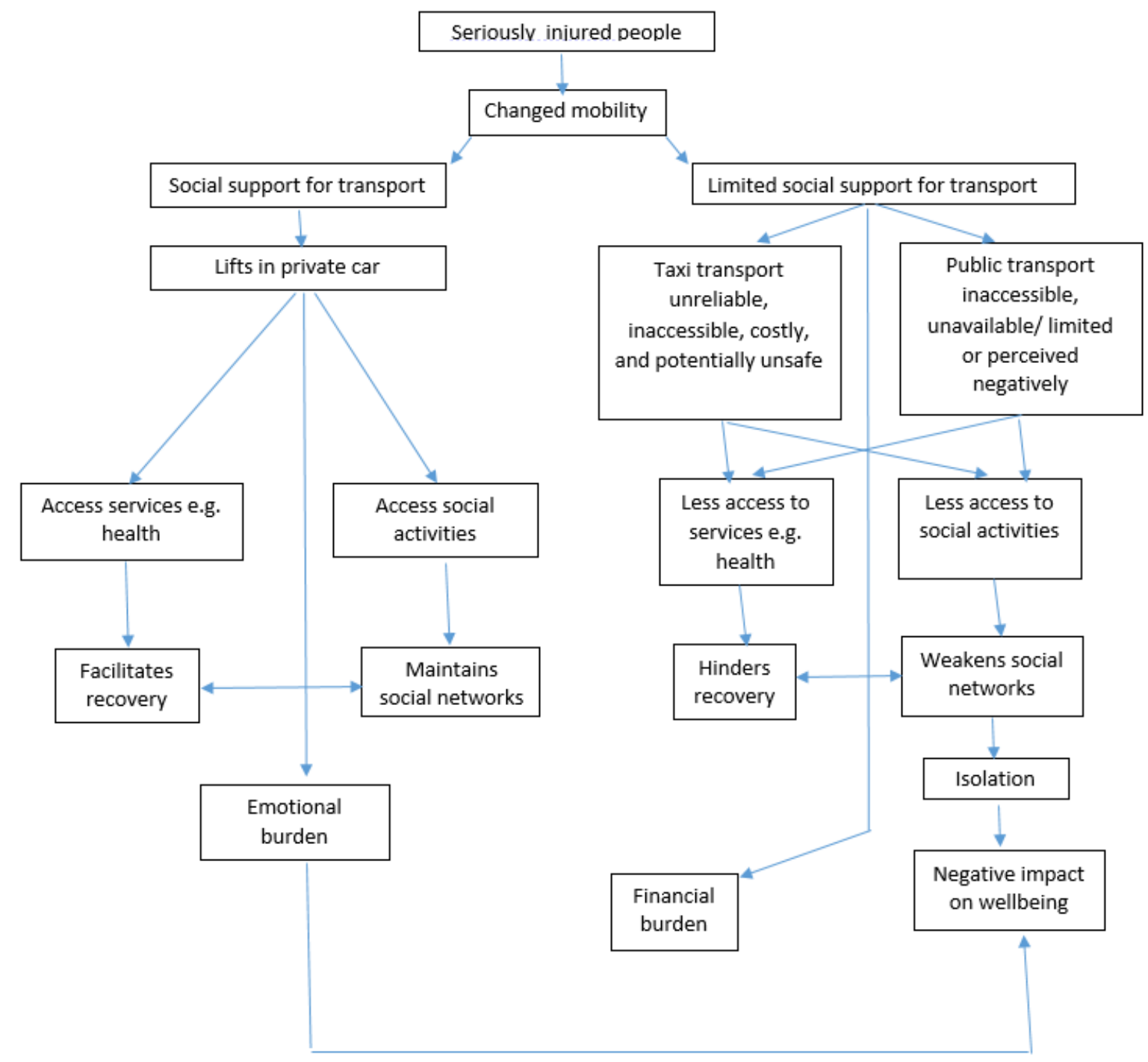


Those with social support networks who helped with travel were able to access services and reengage with social activities, whilst those whose networks could not help did not have their needs and desires to travel met to the same extent. Furthermore, those who were active members of their own social network prior to injury could no longer then provide support to others such as elderly relatives because they could not travel.

Social support after injury is important (Kellezi et al, 2016) and the ability to travel connects people to their social networks and enables them to access that support. If connectivity between people and their social networks is broken, this could negatively affect the health, wellbeing and subsequent recovery of traumatically injured people. This finding is similar to that of research that showed that when the ability to travel is disrupted by events such as floods vulnerable people lose connectivity with friends and relatives and the social support they supply which negatively impacts their wellbeing (Christie et al, 2016a).

Arguably, picking up a phone or using social media could be a substitute for physically maintaining social networks. However, there was clearly a visceral need and desire for participants to actually engage in social activities and the ability to travel had a clear role to play. Research has shown that there is a drive or 'compulsion' for people to meet in person with transport playing a key role in facilitating this given the increasing fragmentation and remoteness of families and friends (Larsen, et al 2006).

\subsection{Strengths and Limitations}

The unique strengths of this work is that it provides an insight into the relationship between travel, social networks and the impacts of this on people's wellbeing. This was a substantive qualitative study, which achieved interviews with over 100 patients 3 years post injury. It reveals the hidden emotional and financial costs which pervade when there is persisting disability which affects people's mobility. The findings of the RESTORE project reveal that the prevalence of ongoing problems in seriously injured patients 3-years post-injury is high. Results show that many patients' report problems with their health-related quality of life (measured using the EQ5D). Problems at 36-months post-injury were reported for mobility (37\%), for self-care (21\%), for usual activities (47\%), for pain/discomfort (50\%), and for anxiety/depression (41\%) (Gabbe et al, in press).

The findings highlight the importance of the social and geographical context in which injured people live and the implications of this for their wellbeing. It shows that practical and financial support could make a real difference in alleviating the sense of being a burden caused by having to rely on social support networks. Addressing this burden could liberate people who already have significant challenges to face. A limitation of the study is that we have not been able to capture the potential burden felt by friends and relatives and the costs they have experienced, it is likely that these are significant. We did not capture the costs borne by families who may have adapted their own vehicles in order to support the mobility needs of their relative. Families may have opted to put access lifts into their pre-existing vehicle; others choose to buy a ready access vehicle, which further adds to the burden of cost. We also did not capture the time costs for families when they take the injured person to the multiple appointments, taking time off work and in some cases, may have ceased working altogether. Whilst this paper focused on the person who had experienced the injury it does not capture the life-long impact on the family and carers. We did not interview people who did not speak English and therefore we may not represent the views they have and potentially any language barriers they experienced in accessing support for their travel and mobility.

These findings are likely to be generalizable to other countries where there is a high dependence on car travel to access services and social networks. Eighty per cent of urban travel in Australia is done by car and this pattern of travel has been stable over the last 45 years. In 2013-14, on an average day each Australian travelled $49 \mathrm{~km}$ which is a longer average commute time than US or Canadian cities 
of similar sizes ${ }^{2}$. For Australians living in rural areas, limited public transport and long travel times to reach destinations can exacerbate social isolation and inequality ${ }^{3}$

\section{Implications for policy and practice}

5.1 Health service providers

\subsubsection{In hospital}

When people with changed mobility are discharged from hospital the discharge coordinator needs to consider whether the person has social networks to support their travel. For people who live in rural (regional) areas questions should be asked about access to public transport. This could form part of a care pathway and consideration of an individual's options to travel and how to achieve this. Such a post discharge plan or care pathway for people with impaired mobility should identify how they are going to maintain their ability to travel. Occupational therapists (OT's) and physiotherapists may well be best placed to discuss this during the patient's rehabilitation and they could make outings with their patients in their local area to assess their needs and whether they can be met. For those directly discharged home the discharge coordinator needs to help the patient make contact with community services that can support their mobility as it is often at this point that patients fall between the gaps (Christie et al., 2016b). Similarly, OTs could link up with employers to discuss supporting the transport needs of their employee in order to help them return to work.

\subsubsection{Local physicians}

Where possible people need to be signposted to OT's to assess their fitness to drive and support their return to driving in adapted and all terrain type vehicles especially for those who live in a rural area. The process outlined by the AUSTROADS ${ }^{4}$ publication "Assessing Fitness to Drive" (2016) is a good starting point. This publication is aimed at health professionals who need to assess a person's fitness to drive following illness or injury and provides evidence on how to make decisions about someone's medical fitness to drive. It also provides general guidelines for managing patients with respect to their fitness to drive. In the UK, mobility centres are also used to assess fitness to drive and to give advice about how to adapt vehicles to accommodate disabilities ${ }^{5}$.

Local physicians could raise awareness of the different types of support available to people with a disability and signpost them to local support groups to help strengthen informal social support networks. This could also cover practical and financial support such as how to access discounted taxi vouchers, extended parking time for those with disabled permits, volunteer services for transport to health appointments, discounted public transport concessions for pensioners, carers and health care cardholders. In addition, they could sign post people to voluntary sector organisations that help to support the travel needs of people with limited access to transport.

\subsection{Public transport, taxis and infrastructure}

Many governmental organisations have passed legislation to ensure that public transport and taxis are accessible and can accommodate disabled people's needs (e.g. UK, Equality Act 2010; The Americans with Disabilities Act of 1990, Australian Disability Act 2006). However, in practice our research suggests more could be done by transport providers (such as taxi companies) to ensure accessible, available, reliable and reasonably priced services are available for people with mobility

\footnotetext{
${ }^{2}$ https://bitre.gov.au/publications/2016/is_075.aspx

${ }^{3}$ http://www.abs.gov.au/ausstats/abs@.nsf/Lookup/1381.0main+features2002013

${ }^{4}$ https://www.onlinepublications.austroads.com.au/items/AP-G56-16

${ }^{5}$ http://www.mobility-centres.org.uk/services/drivingassessment.htm.
} 
impairments. Similarly, local authorities need to make sure that the built environment, transport and recreational infrastructure should be fully accessible to people whose mobility is impaired.

\section{Conclusions}

In order for these suggestions to succeed and have impact where they are most needed, a combined initiative of health professionals, employers researchers, patient advocates, policy makers and legislators working together, is required. Discharge planning needs to be addressed by the health care team on day one of injury. Building up a good relationship with the patient, family and carers is an essential step in the road to recovery and life after hospital. Excellent discharge planning allows patients to re-enter society, post hospital, armed with information, pragmatic solutions and a clear pathway to their 'new normal'. Providing practical assistance in the home environment and in the community in which they live and function, is key to successful re-integration. Occupational therapists play a pivotal role in this and where possible, this should be conducted in the person's environment to truly be able to identify, understand and mitigate the challenges. Lobbying and advocating with key bodies to ensure accessible transport, pathways, roads, entrances etc. is essential to providing the safest, most user friendly system for people with impaired mobility. To make this happen leadership is required at government level, ideally this should come from the Department for Health and Human Services..

In summary, being able travel is important for people who have experienced major trauma because they need to access rehabilitation and health services and reengage with social activities which facilitate recovery and a sense of wellbeing. Social networks are important to support the needs and desires for transport and mobility of injured people. On discharge from hospital, the mobility needs of patients should be considered and catered for to avoid isolation and negative impacts on wellbeing. More needs to be done to ensure that the environment is more accessible for those who have mobility impairments.

\section{Acknowledgements}

We would like to thank the investigators, Steering Committees and the participating hospitals of the VSTR and to express our appreciation to the participants. We would also like to thank Mandy Brown and Dan Myles for their assistance with the interviews.

\section{Funding}

This project was funded by the Australian Government's National Health and Medical Research Council (GNT1061786). The Victorian State Trauma Registry (VSTR) is funded by the Department of Health, State Government of Victoria and Transport Accident Commission. BG was supported by a Career Development Fellowship (GNT1048731), from the National Health and Medical Research Council (NHMRC) of Australia.

\section{References}

1. Barnes, J.A. 1954. Class and Committees in a Norwegian Island Parish. Human Relations, (7): 39-58.

2. Barclay, L., McDonald, R., Lentin, P. and Bourke-Taylor, H. 2016. Facilitators and barriers to social and community participation following spinal cord injury. Aust Occup Ther J, 63: 1928. doi:10.1111/1440-1630.12241

3. Berkman, L.F. and Glass, T., 2000. Social integration, social networks, social support, and health. Social epidemiology, 1, pp.137-173. 
4. Boniface, S., Scantlebury, R., Watkins, S.J., Mindell, J.S. 2015. Health implications of transport: Evidence of effects of transport on social interactions. Journal of Transport \& Health, 2(3):441-6.

5. Braun, V. and Clarke, V. 2006. Using thematic analysis in psychology. Qualitative Research in Psychology, 3 (2): 83. doi:10.1191/1478088706qp063oa.

6. Cameron, P., et al. 2005.The trauma registry as a statewide quality improvement tool. J Trauma, 59: 1469 -76.

7. Carpenter, C., Forwell, S. J., Jongbloed, L. E. \& Backman, C. L. 2007. Community participation after spinal cord injury. Archives of Physical Medicine and Rehabilitation, 88 (4), 427-433. doi:10.1016/j.apmr.2006.12.043.

8. Cass, N., Shove, E., Urry, J. Social exclusion, mobility and access.2005. The Sociological Review, 53(3):539-55.

9. Charlson, M.E., Pompei, P., Ales, K.L., MacKenzie, C.R. 1987.A new method of classifying prognostic comorbidity in longitudinal studies: Development and validation. Journal of Chronic Diseases, 40(5):373-83.

10. Christie, N., Beckett, K., Earthy, S., Kellezi, B., Sleney, J., Barnes, J., . . Kendrick, D. 2016 a. Seeking support after hospitalisation for injury: a nested qualitative study of the role of primary care. Br J Gen Pract. 2016 Jan;66(642):e24-31. doi: 10.3399/bjgp15X688141. Epub 2015 Dec 6.

11. Christie, N., Griffin, L., Chan, N., Twigg, J., \& Titheridge, H. 2016b. Private needs, public responses: vulnerable people's flood-disrupted mobility. Disaster Prevention and Management: An International Journal, 25 (2), 244-260. doi:10.1108/DPM-11-2015-0254

12. Cox, R.J., Amsters, D.I., Pershouse, K.J. 2001.The need for a multidisciplinary outreach service for people with spinal cord injury living in the community. Clinical Rehabilitation, 15(6):600-6.

13. Department of Health. Victorian State Trauma Registry 1 July 2014 to 30 June.2015. Summary report. Victoria 2014.

14. Gabbe, B.J, et al. RESTORE: REcovery after Serious Trauma-Outcomes, Resource use and patient Experiences study protocol. 2015. Inj Prev, 21: 348-54.

15. Gabbe, B., Simpson, P., Cameron, P., Ponsford, J., Lyons, R.A., Collie, A., Fitzgerald, M., Judson, R., Teague, W., Braaf, S., Nunn, A., Ameratunga, S., and Harrison, J.E. 2017. Longterm health status and trajectories of serious injured patients: A population-based longitudinal study. PLOS Medicine. Special Issue on Trauma. In press (Accepted 12th May 2017).

16. Kellezi, B., Coupland, C., Morriss, R., Beckett, K., Joseph, S., Barnes, J., . . Kendrick, D. 2016. The impact of psychological factors on recovery from injury: a multicentre cohort study. Social Psychiatry and Psychiatric Epidemiology, 1-12. doi:10.1007/s00127-016-1299-z

17. Larsen, J., Axhausen, K.W., Urry, J. 2006. Geographies of Social Networks: Meetings, Travel and Communications, Mobilities, 1:2, 261-283, DOI: 10.1080/17450100600726654

18. Levasseur, M., Généreux, M., Bruneau, J-F, Vanasse, A., Chabot, É., Beaulac, C. et al 2015. Importance of proximity to resources, social support, transportation and neighborhood security for mobility and social participation in older adults: results from a scoping study. BMC Public Health, 15(1):503. 
19. Lyons, R. A., Kendrick, D., Towner, E. M., Christie, N., Macey, S., Coupland, C., . . Grp, U. K. B. I. S. 2011. Measuring the Population Burden of Injuries-Implications for Global and National Estimates: A Multicentre Prospective UK Longitudinal Study. PLOS MEDICINE, 8 (12), ARTN e1001140. doi:10.1371/journal.pmed.1001140

20. Marottoli, R.A., Mendes de Leon, C.F., Glass, T.A., Williams, C.S., Cooney, L.M. Jr., Berkman, L.F., et al. 1997. Driving cessation and increased depressive symptoms: prospective evidence from the New Haven EPESE. Established Populations for Epidemiologic Studies of the Elderly. Journal of the American Geriatrics Society. 45(2):202-6.

21. McInnes, K., Friesen, C.L., MacKenzie, D.E., Westwood, D.A, Boe, S.G. 2017 . Mild Traumatic Brain Injury (mTBI) and chronic cognitive impairment: A scoping review. Kobeissy FH, ed. PLoS ONE, 12(4):e0174847. doi:10.1371/journal.pone.0174847.

22. Pointer, S. Australian Institute of Health and Welfare (AIHW).2015.Trends in hospitalised injury, Australia 1999-00 to 2012-13. Canberra: AIHW.

23. Prang, K.H., Berecki-Gisolf., J., \& Newnam, S. 2015. Recovery from musculoskeletal injury: the role of social support following a transport accident. Health and Quality of Life Outcomes, 13, 97. http://doi.org/10.1186/s12955-015-0291-8

24. Social Exclusion Unit. 2003. Making the Connections: Final Report on Transport and Social Exclusion, Office of the Deputy Prime Minister, London.

25. Smith, K.P., Christakis, N.A. Social Networks and Health. 2008.Annual Review of Sociology, 34(1):405-29.

26. Syed, S.T., Gerber, B.S., Sharp, L.K. Traveling Towards Disease: Transportation Barriers to Health Care Access. 2013. Journal of community health, 38(5):976-993. doi:10.1007/s10900013-9681-1.

27. Urry, J. Social networks, travel and talk. 2003. The British Journal of Sociology, 54(2):155-75.

28. Wilson, J., Pettigrew, L. \& Teasdale, G. 1998. Structured Interviews for the Glasgow Outcome Scale and the Extended Glasgow Outcome Scale: Guidelines for Their Use. Journal of Neurotrauma, 15, 573-585. 
